\title{
Practices, Challenges and Opportunities of Inclusive Education Implementation in Kambata Tambaro Zone, Ethiopia
}

\author{
Tesfaye Basha Ludago \\ Hawassa University, Hawassa, Ethiopia \\ Email: tesfayeask@yahoo.com
}

How to cite this paper: Ludago, T.B. (2020) Practices, Challenges and Opportunities of Inclusive Education Implementation in Kambata Tambaro Zone, Ethiopia. Open Access Library Journal, 7: e5989.

https://doi.org/10.4236/oalib.1105989

Received: December 10, 2019

Accepted: February 7, 2020

Published: February 10, 2020

Copyright $\odot 2020$ by author(s) and Open Access Library Inc.

This work is licensed under the Creative Commons Attribution International License (CC BY 4.0).

http://creativecommons.org/licenses/by/4.0/

\begin{abstract}
The purpose of this study was to assess the practices, challenges and opportunities of implementation of inclusive education in Kembara Tembaro zone, Southern Ethiopia. The study used qualitative research method to collect data. This method is concerned with exploring the existing current status of inclusive education practices, challenge and opportunities. Participants of the study were seven district education experts, seven school principals, two education experts of the zone and two education experts of the region bureau included in the study. For data collection interview, document consultation and checklists were used. The finding revealed that there are inadequate infrastructures and education facilities, sanitation facilities, lack of ramps, dirty and dusty classrooms and acoustically non-treated classrooms, equipments and services; moreover, negative attitudes of teachers, lack of budget, limited professionals, lack of responsible personnel in district, zone and region education offices. Parents started to send their children to school; however, there is lack of skilled professionals who will screen and identify according to interests of learners. There is highest number of repeaters and dropouts in early schools because of unfriendly learning environment for diversified learners. The study suggested that high attention is needed from the concerned parties for the implementation of the inclusive education in the zone.
\end{abstract}

\section{Subject Areas}

Education

\section{Keywords}

Inclusive Practices, Challenges, Opportunities, Inclusive Education 


\section{Introduction}

\subsection{Background of the Study}

Education is human right, as reflected in the principle of Universal Primary Education [1], and Education for All goals to which Ethiopia has committed. Ethiopia has ratified the UN Convention on the Rights of Persons with Disabilities in 2006, which recognizes the right of persons with disabilities to inclusive education at all levels of the education system. This enhances its recipients' quality of life, enabling them to become independent, productive citizens with sense of dignity and self-worth. In this regard, inclusive learning environments will aid all children in their learning and meet their potential. Again, it promotes social equity and eliminates discrimination among the disabled. Inclusive education is more cost-effective than the creation of special schools across the country, especially in the rural areas.

Inclusive education is a democratic setup, which relies on equal rights and equal opportunities [2]. So, to make sure that the disabled are accepted, respected and not discriminated in schools becomes necessary [3]. It also emphasizes that educational environment must be adjusted to meet the needs of all learners. Children with special needs meet a wide range of barriers in learning. Often, these learning barriers are associated with inclusion, and involve several factors such as quality of assessment, placement, quality of services, interaction between disabilities and teachers, socio-cultural environment and availability of facilities. Quality of service is one of the main aspects of successful implementation of inclusive education [4].

So far as socio-cultural environment is concerned, the parents belonging to the low socio-economic status of society are lack of awareness about disability education and hesitate to send their kids to special schools as well as inclusive schools [5]. Besides, [6] found that the majority of teachers hold neutral or negative attitudes towards the inclusion of pupils with special needs in regular primary education.

On the contrary, strength of current inclusive education system, the Ethiopian Constitution establishes the universal right to education and emphasizes the need to allocate resources and provide help to disadvantaged groups (articles 41 and 91). Ethiopia has ratified various international conventions and instruments of relevance to inclusive education. Of particular significance is the UN Convention on the Rights of Persons with Disabilities, 2006, in which Articles emphasize inclusive education. The 1994 Education and Training Policy of Ethiopia is for providing education for all children. On the other hand, government commitment to universalizing primary education to all criticizes is not only a right but also a guarantee for development. A wide range of NGOs and organizations representing people with disabilities are playing an active role in promoting and implementing inclusive education in Ethiopia. In addition, ESDP IV has much described future developments in inclusive education.

The second new special needs education strategy [7] addressed problems de- 
spite rapid expansion of the education system; however the sector faces several key challenges relevant to the education of special children. These includes: limited access to education for the most vulnerable children, achievements in access have not been accompanied by adequate improvements in quality, weak capacity to plan, manage and check the education system, low-level of awareness and capacity to address special needs education in schools, out of school children, drop-outs, repetition, negative attitudes, poor teaching skills, insufficient trained support staff, inaccessible and unsafe built environment, insufficient materials, lack of interpreters for deaf learners, graduates from special needs lack practical skills and etc.

As indicated by South Nation Nationalities People Region [8] the current status of education office task is encouraging in participation and supporting special needs children in education systems. These can be described as follows: developing five years strategic plan and disseminating the plans to zones and special districts, producing different guidelines, capacity building for schools, establishing resource centers, trainings, support for colleges engaged in training special needs education professionals and providing awareness raising programs. Despite these supports SNNPR education sector faces different challenges in the education system such as not paying attention for budget for inclusive education, unorganized education development, lack of responsibility to lead inclusive education, looking disability issues as NGOs issues, lack of guiding inclusive/special needs education as a policy issues, lack of resources, limitation of professionals and lack of adequate awareness in society and stakeholders on inclusive education [8]. It is important to note that proper inclusion is possible when we remove the above barriers and give placement according to the productivity of the child and facilitating competitive academic achievement environment in inclusive schools.

Based on above arguments, inclusive education requires a commitment and accountability to the underlying philosophy from educators at all levels of the education and support from the stakeholders. Hence, a feasibility study needs to be carried out to find out the practices, opportunities and challenges of inclusive education at zonal level. It is in this milieu, that the present study has been planned.

\subsection{Statement of the Problem}

In Ethiopia, schooling for students with special needs is evolving at a rapid rate due to educational and legal changes in the country. In most cases, these changes might have its own contribution in giving access to the education of the people with disabilities. Currently, special classes and inclusive schools for the children with special needs are increasing in number gradually. These nationwide movements toward opening integration classes in regular schools are part of the inclusive education movement and the result of the expansion of the inclusive education program. However, inclusion should not mean dumping children into the regular education classes. Teachers have to make sure quality education for 
all. Quality education does not simply mean cognitive learning. Human values, attitudes, skills and competencies are also important. Guaranteeing and about the right to education in the neighborhood school is a challenge which every teacher has to meet with dedication and sincerity otherwise inclusion will be a frustrated attempt, if not a disaster.

These new paradigms shift to inclusive education of the country show a need to investigate about implementation of inclusive education in terms of its practices, opportunities and challenges in current school settings. In this regard, [9] stated that the current movements of inclusion of pupils with special educational needs in mainstream schools should be assessed in terms of its potential impact on pupils' academic performance as well as its impact on their social adaptation. This requires an in-depth study in implementation of polices in the education system of inclusive primary schools.

Hence, focusing on inclusive education, this study will attempt to check practices, opportunities and challenges of children with special needs in inclusive primary schools of Kembata Zone.

- What are the practices of inclusive education implementation in Kambata Tembaro zone?

- What are the prevailing environmental, administrative, social and academic challenges of inclusive education?

- What are enrollments, retention and dropouts practices in inclusive education settings?

- What are the opportunities of implementation of inclusive education in Kambata Tembaro zone?

\section{Research Design}

The qualitative research approach was used for this study. The researchers used two methods of data collection-interviews and observations-to obtain thick data [10]. The researcher interested in gaining an insight about the school principals, district, zone and region education experts about the implementation of inclusive education current practices, challenges and opportunities in the zone. Therefore, the researcher used qualitative framework to obtain thick data in implementation of inclusive education and lived experiences [11].

Analysis of the data agreed with the research questions and revealed themes that emerged from the responses to the questions. Four major themes emerged from the analysis. The themes consisted of issues related current educational status of students with special needs in terms of enrolment, retention and dropout, practices of inclusive education, roles of school headmasters, Woredas, Zone, Region Education Offices to enhance the effectiveness of inclusive education and efficiency of teachers, prevailing challenges of environmental, administrative, social and academic practices in inclusive education.

The researcher had two purposes to understand education expert's view in the implementation of inclusive education and to present a summary of interview findings. 


\subsection{The Sampling Procedure}

The study sites in the zone include seven districts. Out of seven districts primary schools seven special classes and inclusive teaching schools were selected. From these schools sum of seven school principals, seven districts, two zone and two region education experts participated in the study. School principals, districts, zone and region education officers were selected by using available sampling methods.

\subsection{Interviews for School Principals, Districts, Zone and Region Education Experts}

The interviews for the 18 school directors and experts were conducted with two main aims in mind. First, the aim was to explore administrative activities in the implementation of inclusive education of children with disabilities and their difficulties in teaching and learning processes. The interview mainly focused on five categorical areas like practices, opportunities, challenges, enrollment/dropout/repetition and implementation of inclusive education. To obtain the required information in this regard, the researcher administered open ended interviews. Finally, the collaborative efforts of principals and experts to solve the problems were addressed.

\subsection{Methods of Data Analysis}

Qualitative method of data analysis was employed. For qualitative data, narrative description and verbatim were used.

\section{Results of the Study}

The purpose of the interview was explained to the experts both at the time of making arrangements and just before the actual interview sessions. Experts were asked to respond to semi-structured interview questions. As much as possible accuracy of interpretation was ensured by using experienced researcher to validate the interpretation. The purpose of the interview, as mentioned earlier was to obtain information from education experts about their practices of inclusive education under four main headings:

- Practices of inclusive education implementation,

- Challenges of environmental, administrative, social and academic practices in inclusive education,

- Educational status of students with special needs in terms of enrolment, retention and dropout,

- Opportunities of implementation of inclusive education. In addition, experts were also asked to give their suggestion about measures to be taken in order to improve inclusive education. The result of the interview is presented according to the above four response categories.

\subsection{Interview Results of Educational Experts}

Table 1 demonstrates a total of seven school principals, seven educational 
Table 1. Demographic characteristics of participants.

\begin{tabular}{|c|c|c|c|c|c|c|c|c|c|}
\hline No & Participant & Age & Sex & Zone/Region & Specialization & Position & Work exp. & Training SN E & Teaching exp. SNE \\
\hline 1 & District expert & 35 & M & Kambata T. & Curriculum & Expert & 6 & No & yes \\
\hline 2 & School 1Director & 32 & M & “ & EDPM & Director & 5 & No & No \\
\hline 3 & District expert & 34 & $\mathrm{~F}$ & “ & Special Educator & Expert & 6 & No & No \\
\hline 4 & School 2 Diector & 27 & M & “ & Biology & Director & 3 & Yes & No \\
\hline 5 & District expert & 28 & M & “ & Special Educator & Expert & 4 & Yes & yes \\
\hline 6 & School 3 Director & 27 & M & “ & Leadership & Director & 5 & yes & yes \\
\hline 7 & District expert & 30 & $\mathrm{~F}$ & “ & Special Educator & Expert & 11 & No & No \\
\hline 8 & School 4 Director & 39 & M & “ & Leadership & Director & 10 & No & Yes \\
\hline 9 & District expert & 42 & $\mathrm{~F}$ & “ & Psychology & Expert & 13 & Yes & Yes \\
\hline 10 & School 5 Director & 34 & M & “ & History & Director & 10 & No & No \\
\hline 11 & District expert & 36 & M & “ & Special Educator & Expert & 12 & Yes & No \\
\hline 12 & School 6 Director & 37 & M & “ & Geography & Director & 11 & yes & No \\
\hline 13 & District expert & 36 & $\mathrm{~F}$ & “ & EDPM & Expert & 10 & yes & Yes \\
\hline 14 & School 7 Director & 41 & M & “ & EDPM & Director & 8 & No & Yes \\
\hline 15 & Zone Experts & $35-40$ & M & “ & EDPM \& Pedagogy & Expert & 10 & No & No \\
\hline 16 & Region Experts & $40-50$ & $\mathrm{M}$ & SNNPR & Curriculum \& Social & Expert & 15 & No & No \\
\hline
\end{tabular}

SNNPR: South nation nationalities people region, SNE: Special needs education.

experts of district, two zone and two region were purposefully selected for the implementation of inclusive education under study. From each school one principal was selected. All the participants volunteered to take part in the interviews according to the time arranged between the researcher and each participant. All interview participants age range from 27 to 50.16 males and 4 females' experts participated in the interview; all interview participants were hearing people.

\subsubsection{Knowledge of Inclusive Education}

Most of the school principals' responses to the first question were that they took special needs education as a common course at the higher institution, workshops, seminars, on the basis of awareness level and few of them after the assignment as principals. Some of them attempt to state that knowledge of inclusive education has developed towards the idea that all children and young people, despite different cultural, social and learning background, should have equal learning opportunities in all kinds of school. The focus is with regard to, understanding and taking care of cultural, social and individual variety, the provision of equal access to quality education, and close coordination with other social policies.

Seemingly, one of the principals uncovered his experience that inclusion is focused on providing educational opportunities and meeting all students' needs through individualized supports. Every child will struggle at some point so we 
ensure that there should be a support; mostly, in placement for those children, hence, inclusion occurs in a context that supports student diversity.

In line with this, the other principals noted that inclusive education can be seen as a process of strengthening the ability of an education system to reach out to all learners. Inclusion is participation and success of all learners. He explained the importance of inclusive education; it is a means to understand the right of high quality education without prejudice and having equal opportunities.

On the other hand, some of the principals reported that:

"We know inclusive education by name. We know inclusive education is inclusively teaching children with disability in regular settings. As a principal, we don't have adequate knowledge about these children how to treat in our school. In our schools we had one special needs professional recently. Regular teachers without knowledge naturally supporting them."

This shows that some school principals they don't have knowledge to carry out inclusive education in regular education system. They suggested awareness creation and training for school principals is important to implement inclusive education.

Most of the districts education experts reported their understanding of the concept of inclusive education through common course, seminars, and workshops and after education office assignments. They understand since they have responsibilities to know the types of disability and inclusive education. It is also current government's direction. They addressed that limited understanding of concept of disability and negative attitude towards persons with disabilities and prejudice are still continued conditions that affect clear understanding and valuing of all learners.

The zone education experts reported about inclusive education understanding that through common courses, seminars, workshops and after assignment of education office. When they forward their concept of understanding inclusive education, it is on the education strategy, policy of education, constitution and on child right, Salamanca statement and different international and national conventions of human rights. The assignment of office task requires carefully understanding policy directions and education systems as basis for the implementation of inclusive education approach. Some also reported that they don't know about inclusive education strategy in ministry of education and are not knowledgeable about inclusive education. This shows that some assigned officials lack adequate knowledge of inclusive education and experiences in current inclusive education strategy.

The region education experts about their understanding of inclusive education reported that through seminars, workshops and after assignment of education office. When they forward their concept of understanding inclusive education is on the education strategy, policy of education, constitution and on child right and different international and national conventions of human rights. The assignment of office task most important to carefully understanding policy di- 
rection and education systems are basis for the implementation of inclusive education approach.

\subsubsection{The Practices of Implementation of Inclusive Education}

Concerning the practices of inclusive education some principals revealed that teaching pupils with special needs in the inclusive classroom no doubt implies adaptation of the standard curriculum. Teachers are confronting with the question of how to instruct these pupils. Pupils with special needs may require more instruction time or other teaching methods and professional knowledge. In that case, teachers fear the need of more time, materials and knowledge.

However, whatever the difficulties, some principal stated that teachers always bear in mind that he/she, as a teacher, has a very important role to play. It is the pupils who meet barriers to learning that mostly need their support. Strategies to meet special needs are simple and when they are applied, they benefit all other pupils in their classroom too. They noted that most of their schools may not be able to accommodate learners with various diversities of learning needs. The principals reported that some problems as lack of understanding of the inclusion philosophy by the teachers. Principals added that some of the problems like school community awareness limitation, poor teaching and learning approaches, lack of or inadequate adaptations in public and private buildings to allow easy access mobility to persons with disabilities, fear of responsibility and stress from added responsibility, lack of early screening, identification and intervention, etc.

On the other hand, the communities fail to support inclusive education; parents prioritize taking other children without special needs to school and only considering the one with special needs if finances are still available, low expectations from the learners with special needs leading to low self esteem in the learner. Some school administrators and policy makers in education feel that it is improper to "waste" scarce resource on learners with special needs and poor or negative attitudes towards disability engagement in their classrooms. In addition, principals added that there are limitations of professionals, material and resource support for schools and lack of encouragement to promote inclusive education.

Regarding the readiness of teachers, the principals revealed that teachers are limited by professional knowledge and skill to treat these exceptional children. They indicated the reason that most grow up and teaching regular students in regular education system. Therefore, they follow the traditional way of teaching. The teachers have low expectations from the learner with special needs and may not give him/her challenging work. Thus may make the learner give up trying, as his/her efforts are not appreciated. They are not free from traditional approaches, practicality, student centered and individualized educational supports are not exercised. Teaching and learning take place in a haphazard manner, teaching methods are traditional (chalk and talk), teachers are not equipped to match the learners with their diversity needs, and learners suffer from problems of inadequate support. Teachers lack of individual attention to learners due to large 
teacher: pupil ratio. In this regard, many invisible children with learning difficulties are suffering from unjust education system in regular classrooms. However, they started to attend the schools. Students with special needs are not profitable in the academic education as a result of above mentioned reasons. Hence, the implementation of inclusive education is highly problematic due to lack of positive attitudes of teachers, school administrators, economic support, communication and language problems, absence of supportive bodies, shortage of trained teachers, lack of commitment and follow up from stakeholders and lack of conducive learning environment.

In addition, schools are limited flexibility of the curriculum because learners are exposed to the same curriculum whereby they are expected to pass the same examinations. Some learners cannot cope with the extensive content of the classroom. This is teachers' inability to diversify the curriculum to suit individual learner's needs. Furthermore, teachers, inability to communicate in a medium of instruction which the learner understands like Sign Language, Braille reading and writing.

Most schools are not ready to accommodate diversity of learners because of negative attitudes of teachers and school communities. Teachers are not ready in attitude, profession, knowledge and skill. Only limited special needs groups are beneficiaries to some extent like hearing, visual and physical impairments in schools. Almost no provision for educating some groups of learners such as the gifted and talented, autistic children, children with intellectual limitations, hard of hearing, partially hearing, communication problems, learning difficulties as well as those living in difficult circumstances. To achieve inclusive education goals in the schools as well as in the zone appropriate educational services can be detrimental to the academic and social outcomes of these children.

With regard to current practices of inclusive education most District education experts addressed that a number of positive achievements were made in producing qualified professionals, however, limited in number and distribution differ from district to district. Schools started to admit a number of special needs students, few workshops, for the evaluation of implementation of inclusive education there is a checklist however it differs from district to district, house to house assessment more or less in all district, community mobilization activities are taking place to bring out of school children.

Pertaining inclusive education practices the zone education experts reported that material and professional support for school have limited support. The zone education expert stated that the major central issue is that there is no responsible person in zone and district education office level to run activities of inclusive education in possession. The sector is attached under teaching and learning core sector. The challenge in the core sectors is no responsible special needs education professional for those who are left behind school children. There are no assigned professionals from district to region to run the inclusion. One of the zone's education experts stated that: 
"Now time, children with different diversities coming to regular schools to attend in regular classes and units. From year to year their number is increasing. The problem is ownership problem, responsibility problem to carry out inclusive education."

This shows that in all districts as well as in the region whole there is no appropriate owner professional for inclusive education in all core education sector offices. All zones experts believed that it is necessary to allocate special needs education professionals in all levels of learning and teaching education sectors for the implementation inclusive education.

Regarding physical facilities and supports, some of the education experts of the zones reported that the physical facilities of school help to enhance the learning of the students. However, in most schools availability and accessibility of the physical facilities including drinking water, electricity, toilets, furniture, playgrounds, libraries, laboratories, resource rooms are not fulfilled, which have a significant impact in academic and vocational achievement. They added that the schools' physical environment is the basis of quality education. However, schools with improvised or inadequate physical facilities do not produce good results. Particularly, students with physical impairments to enter easily through the main gates of the school, buildings, lack of ramps, entrances pavements of classrooms, dining rooms, supportive educational physical environment, offices, and accessibility in terms of information which includes sign language, printed/written form and Braille were found inaccessible. This shows that in the region there is inaccessible and unsafe environment of learning in many schools. Hence, it is conceptualized as a barrier to learning and development that need to be removed. The classroom should be wheelchair friendly, doorway should be widened, and stairs should be removed and be replaced with ramps to allow movement.

Concerning curriculum, many of the respondents viewed as one of the barrier to learning and development in the classroom. It is important that the curriculum should be flexible enough to accommodate all learners in the classroom; otherwise, it could lead to learning fail. Some of the experts attributed barriers to learning are inability of education system to accommodate diversity from accessing educational provision. This requires additional planning and modifications in order to assist them to learn. One of the zone education experts said that:

"A true understanding of each learner's background, strength, unique abilities, needs and barriers, and then use this information to inform planning and at the end giving a clear center of attention."

This indicates that if the child fails to learn, the problem is not from the child, the problem is from the system and method of teaching. If the curriculum is not flexible it can cause problems for learners because it will not meet their divers needs, Therefore, this requires, identifying the child and appropriate intervention should be provided.

In addition, education experts of the zone addressed that lack of the budget to 
implement inclusive education is one of the barrier, particularly; encouragement of special needs educators and children with disabilities. In addition, both zone education experts said that there is no budgetary plan for the inclusive education implementation. The respondents view that encouragement pay for both parties it is helpful to stay in school and encourages parents to bring the children with disabilities to schools. This shows that Zone and Districts are insisting budgetary plan direction from the region. This indicates that budgetary direction will be expected from the region.

Most of the experts revealed that it is difficult to teach effectively in classes for over sixty or above students together children with special needs such as speech difficulties, sign language, those needing Braille and others. So the class size is one of the challenges in the implementation of inclusive education. Respondents were also explained that for good dissemination of information, knowledge and professionalism and skill needs to inclusion. Hence, it is not only accommodating children in the regular or general school rather it goes beyond that, it focuses on creating environments responsive to the differing developmental capacities, needs and potentials of all children.

The zone education experts stated that house to house community mobilization helped in searching children who have different types of disability and make them to be enrolled in the schools. However, this house to house community mobilization assessment activity has its own gap. There is no policy direction in structured form of mobilization to implement inclusive education with proper identification and intervention.

When asked whether the zone is using special needs professionals appropriately or not, almost both of the education experts said that zone is not properly using trained special needs educators. One of the zone education experts told that:

"In our zone there are 285 schools primary and secondary schools out of these, only 8 trained special needs education teachers. This is insignificant numbers of professionals found only in limited access in schools. With these numbers of professionals inclusive education may not be achieved as expected demand. Most districts they don't want to ask trained professionals, even they respond embarrassing answers, 'what they will do'. Here, there is a big attitudinal problem with education officers for the implementation of inclusive education."

This shows that only $2.8 \%$ of coverage of special needs education professionals in the zone. In addition, there is resistance of change office holders educational experts is one of the challenges for the implementation of the inclusive education. A zone doesn't want to hire trained special needs professionals and even they don't want to send teachers for in-service and regular program training of special needs education.

Regarding the current regional practices of inclusive education, the region education experts reported that inclusive education is a process, understanding, addressing and responding to the diverse needs of all learners through persona- 
lized learning and identifying and removing barriers of the education system. Responding to different needs requires different skills and knowledge and different skillful professionals. The skilled professionals' distributions in schools are only $2 \%$ or less. The region education experts added that identifying and screening children with disabilities and special needs is a big challenge in the schools. Children with disabilities and special needs started to come to school but lack of professional who will screen and sort them with their interest is the current school's challenge. This is home task for the region for training professionals and developing screening instrument.

When the region education experts asked whether responsible personnel for inclusive education from woreda to regional office level or not, they reported that the main important thing is creation of organized and structured system for the implementation of inclusive education for customers and who serve them. In all level of districts to region education offices, there is no guideline for special needs education professionals' job description.

In addition, they reported that there is no concrete budgetary plan to inclusive education except common school grant. There is no budget to encourage teachers and children with disabilities as a bonus for the support of teaching and learning process. If there is no budget, the implementation of inclusive education activities would be ineffective in process.

Regarding educational challenges, education experts of the region revealed that there are challenges during including children with disabilities. Teachers are not ready/committed to support, modify the curriculum based on their interest and ability of learning. This is because inclusive education by itself new for regular teachers. They also added that in schools little or no support for diversity of learners. This shows in regular inclusive schools educational unfairness is one of the biggest problems in teaching and learning process of children with special needs.

Teaching methods are chalk and talk, questioning and answering are dominant ones. Teachers are dominated by this traditional way of teaching methods; they are not free from this method. Continuous assessment, cooperative and student centered learning are not actively used. The teaching system is not attractive for diversity of children; it is pouring in one direction which is not delivered according to needs and interests of the learners. Teachers are not adequately trained/ skillful to modify the curriculum for these diversified children. They don't have adequate knowledge about how to treat specific needs of children in regular schools. The curriculum itself is not encouraging the varying groups of students. Skillful teachers and committed teachers are needed to implement inclusive individualized educational approach. Empowering the learners according to their ability is required from the committed professionals.

Furthermore, experts reported that environmental, social, educational and administrative challenges are prevalent problems of inclusive education. Societal, administrative as well as parental attitudinal problems towards children with disabilities are still continued in every section of services. One of the region 
education experts for administrative challenge told that:

"In administration particularly in bottom school and district level few create conducive learning environment, classrooms built comfortably, some schools status are strong, some are weak, some admit special needs education professionals and special needs children, some schools non considerate. Some use special needs education professionals, some are not, some say what they will do in schools, some even not respond. Some because of lack of consideration they don't take actions, there are prevalent administrative problems."

The above statements indicated that uneven teaching and learning environment professionally, attitudinally, emotionally to run inclusive education.

The participants forwarded that inaccessible environment for learners with special needs in infrastructure, resource, classrooms and material arrangements biggest challenges. Most of the learning centers are physically inaccessible to all because they were not built to accommodate the physically disabled learners. The sizes of desks and lack of enough spaces in the classrooms to cater for all learners who use crunches or wheelchairs are some common challenges in the schools. This indicates that learners will be unable to have access to those places without ramps, which is a form of discrimination.

Regarding curriculum modification all of the region experts stated that curriculum modifications with teachers based on diversity, most of the learners with special needs are not beneficiaries in regular education system. There is no trend of curriculum modification. In this regard, curriculum favored to regular students. It is limited by teachers' knowledge, skill and attitude. There is no educational fairness for children with disabilities. This is attributed to the present primary curriculum that doesn't serve the needs of the children with disabilities. In this case, many of the children with disabilities learn the curriculum which does not belong to them. This causes gaps in education of children with special needs and disabilities and quality of education by itself.

The other challenge is documentation problems. In most districts and zone there is no modern documentation of children with special needs and disabilities. This is the indication of lack of systematic organization document of children with disabilities and special needs status in their categories in the regular education system.

The region experts repotted that the number of children with special needs and disabilities reach 60,334 with 228 special needs education professionals. There are 53,048 (88\%) of children with disabilities enrolled in primary schools ( 1 - 8 grades) in the region. There are $7286(12 \%)$ children with disabilities are attending in secondary high schools. 33,217 males and 27,117 females totally 60,334 children with disabilities are currently attending in regular and special schools.

\subsubsection{Environmental, Administrative, Social and Academic Practices and Challenges}

School principals addressed some school environmental challenges from differ- 
ent schools situations; schools lack proper and adequate facilities and infrastructure such as sanitation facilities, ramps, dirty and dusty classrooms and no acoustically treated classrooms. Furthermore, there are inadequate educational facilities, equipments and services for children with special needs including those with disabilities. Schools are not ready with teaching resources like teaching aids.

Concerning communities' participation in inclusive education, principals explained some challenges that in many communities in the country, disabilities are explained to be resulting from God's punishment for some wrongs done to the ancestors or to some person's problems. As such, the child experiencing any of these conditions is seen as a curse or possessed by the spirits. Such superstitions have led many parents who give birth deviate from the 'normal' to hide the child, hence deny him access to education. Communities low expectations from the learners with special needs leading to low self esteem in the learner. This society's traditional prejudice affects parents to bring their children to regular schools and to contribute their share to inclusive education.

Similarly, principals forwarded that there are administrative challenges that principal attitudes and actions were a decisive factor for the successful inclusion of children of varied ages and disabilities. The school principals viewed it as their role to create an inclusive atmosphere in their school. One of the school principal stated that:

"My main responsibility was to provide leadership and guidance in the school setting so inclusion could be practiced effectively and successfully."

Pertaining opportunities to implement inclusive education, most principals in the selected schools forwarded that there are fertile international and national conventions, constitutional and education and training policy background for the implementation of inclusive education. Society, community, and parental attitudes are changing towards person with disabilities from time to time. Regular schools started to admit CWDs and parents started to send their children to regular schools. In different places students with special needs began to learn in special classes/units and in inclusive settings. Special needs professionals are training in different universities and colleges. The regional government started to give due attention to the implementation of inclusive education. Building resource rooms are started in different places of the region. This shows that there is optimistic environment for the implementation of inclusive education.

All the principals to improve inclusive education in school environment they reported that there is a shortage of skilled man power in the area. This requires professional development to fulfill the gap of trained personnel. There must be feelings of ownership and responsibility for inclusion from the authorities, creating the essence of a supportive school atmosphere, always preparing and willing to adapt instruction to promote inclusion, accountability for administrator beliefs and promotion of inclusion and diversity, budgetary plan, fulfilling the resources, improving school schools infrastructure and changing the negative attitudes of teachers, administrators, parents, communities as well as society 
to the philosophy of inclusive education.

Most of education experts of districts reported some challenges for the implementation of inclusive education that material and professionals limitation in schools, lack of budget, still negative attitude of teachers, limited utilization of professionals, identifying and assessment problems of children in different categories, material and moral support limitation for professionals, lack of responsible personnel in district level, district schools support limitation, most of inclusive activities run by schools by their own, no budgetary plan to expand inclusive education unless school grant, lack of conducive learning environment and community awareness problem are some of the common challenges.

Experts of District/Woredas revealed that for the implementation of inclusive education to support teachers in policy directions still a clarity gap. There is shortage of trained professionals to direct inclusive education in different places. Lack of accountable professional in district office level is a serious problem to implement inclusive education. No budgetary plan at district level for the implementation of inclusive education. There is no budget allocation for professionals' encouragement, for supportive materials like Braille, printed materials, translated books based on their grade levels as well as sign language skilled person. These also cause problems for proper application of inclusion.

Experts reported that most teachers have not been exposed to special needs classrooms and this can be a disadvantage. Educators need to coordinate efforts and understand the needs of the classroom in terms of developing skills and individual education plan. Environments handicap a person in inaccessible public buildings, lack of wide-door, bath rooms, inaccessible public transportation, and negative public attitudes towards persons with disabilities. In Ethiopia, for example, where there are a great number of tribes, cultures, beliefs and religions, the expectation to the child can vary from culture to culture.

\subsubsection{Enrollment, Retention and Dropout of Students with Special Needs} When all the principals were asked to the enrollment of children with special needs, they reported that currently the numbers of special needs children enrollment rates are increasing from time to time. Some of the principals elaborated about the enrollment progress of their school positively, parents started to send their children, however, a significant number of children who start primary school are not completing the first cycle because of inadequate treatment/support and unfriendly learning environment conditions of regular classrooms.

One of the principals reported that there are many causes for the dropouts. Few of them are negative attitudes, school location, poor quality educational provision, inflexible curriculum, poor physical environment and lack of trained professionals in regular schools. Most of the principals reported that out of repeating children in annual summary of the school data, majority of them are special needs children. They forwarded the reason as rigid curriculum, lack of experiences of regular teachers to treat these children and absence of teachers 
and peers support in their limitations. Thus, it is not surprising that drop-out and repeat rates of students with special needs increase because of serious and comprehensive unpreparedness of schools.

Educational expert's perceptions and attitudes are key to successful inclusive practice. However, there is the lack of support from principal sides was observed.

According to education experts of districts the education condition of children with disabilities is bound of traditional negative attitudes, prejudice and discrimination. Typically disability is viewed as a difference, a characteristic that sets individuals apart from everyone else, something that makes the individual less able or inferior. The mode of delivery and the rationales behind providing special needs education are very much influenced, even determined by the several outlooks or assumptions about disabilities and consequently challenging. They need special materials, teaching techniques, or equipment and facilities may also be required. They reported that special education is, first and foremost, individualized education for or additional educational support to children with special needs. Consequently, it requires a lot of struggle and commitment to overcome attitudinal and social barriers. However, the most important thing is bringing attitudinal change and the reorganization of learning environments and school activities.

Consequently, most of the district education experts revealed that any change requires effort and time, innovation, and sensitivity. In this case, in school enrolment of children with special needs teachers attitudes are seen as the decisive factor. Teachers are willing to admit students with disabilities into regular classes and be responsible for meeting their needs. However, regular classroom teachers do not perceive themselves as having the appropriate training and skills to meet the instructional needs of students with disabilities. For this reason, the enrolment of these children is very limited in regular settings. Some of special needs were not recognized in schools, still continued in invisible situation. However, most of the district education experts reported that the enrolment of children with disabilities increasing from time to time.

On the other hand, education experts explained that from school children most of the dropouts and repeating students are special needs children. Low achievement of pupils is one of the major reasons that cause students to drop out. Low achievement is the result of low quality of instruction according to the needs and interests of child in primary education that low teacher motivation and commitment caused educational wastage. Under these conditions, teachers constitute the real bottle-neck of the education system. Attitudes, abilities, skills can have significant influence on the child's participation in education. Furthermore, teacher's attitudes and abilities, lack of material and financial support, lack of coordinated support system in schools from teachers and schooling environment and lack of qualified and motivated teachers who would understand the problems of diversified learners to drop out.

When asked Zone education experts whether educational enrolment of child- 
ren with disabilities increasing or decreasing, they responded that there is a progress in enrollment rate from year to year; however there is no sound enrollment data recorded. So, the achievement in relation to enrollment is very low. The attribution for low enrollment of children with special needs in school is low awareness and unfriendly environment and attitude, inadequate capacity to address special needs education, and inadequate support system for implementation of inclusive education program.

To improve the condition of enrolment the education experts forwarded that awareness raising and acceptance of diversity and learning in inclusive education. They added that strengthening teacher education, improve skills of teachers who admit diversity of children, improve screening and assessment skills of professionals, establish structure of inclusive education at all grade level, improve physical access in school and improving the existing education system.

Both of the region education experts reported that the current enrollment status of children with disabilities and special needs is encouraging. Currently, majority of the population started to understanding inclusive education, parents started to send their children, and teachers started admitting children with disabilities in regular schools. More or less, condition of acceptance in regular education system is increasing. In this regard, enrollment of children with disabilities and special needs improving from previous conditions. The experts exemplified as in 2014 the enrollment of children with disabilities and special needs are 2700 , now in 2018 rising about 60,334 in regional level. This shows how much the regional government pays attention for inclusive education and community awareness level is increasing.

Experts indicate that the field has a lot of problems and that require a lot of attempts. Children come with diversified interest of learning requires knowledge, attitude and skill of teaching and treatment. The schools demand trained and skilled professionals to treat children with diversified learning.

\subsubsection{Role of Education Experts in the Implementation Inclusive Education}

Pertaining to the role of district education experts, the experts stated that school administrator(s) provide a vision and leadership and welcome all students into their school. Collaboration among general educators, special educators, and other school personnel occurs on an ongoing basis in inclusive schools. They added that teachers, parents, communities, school authorities, curriculum planners, training institutes and entrepreneurs in the business of education are among the actors that can serve as valuable resources in support of inclusion. Some (teachers, parents and communities) are more than just a valuable resource; they are the key to supporting all aspects of the inclusion process. This involves a willingness to accept and promote diversity and to take an active role in the lives of students, both in and out of school. The optimal learning environment for inclusion depends largely upon the relationship among teachers, parents, other students, experts and society. Ideally, effective inclusion involves 
implementation both in school and in society at large.

Negative attitudes towards differences and resulting discrimination and prejudice in society manifests itself as a serious barrier to learning. However, it is a barrier that can be overcome through the practice of inclusion and is not a necessary pre-cursor to the process. Education experts have a great role in the implementation of inclusive education changing attitudes of school community as well as society at large exercising the power at the district level. Schools with strong administrative support and commitment were able to effectively serve more students with exceptional needs in general education.

Some District education experts addressed that educational experts have responsibility of making sure that all staff has access to opportunities to learn more about inclusion strategies that develop an inclusive school. One district education expert indicated that principals are in a best position from which they know what is going on in their school to bring access. They are in a better position to identify needs for improvement because of greater contact with students and staffs as well as outside agencies at the same time. They are expected to be the managers of improvement, creating in their schools the right atmosphere for inclusion. They need to have a clear sense of direction for their schools and, in collaboration with their staff, discuss and draw up plans of how to get there.

The zone education officers response to this theme was regular classroom teachers, and school administrators have the major responsibility for inclusive education implementation. The school administration (i.e., principal and vice principal) can have a critical influence on the success of authentic inclusion in schools. They also added that a proactive school management and leadership as an indicator of success in creating an inclusive school. The support provided by school administration in implementing inclusive education values for special needs learners in mainstream primary schools.

All experts further explained leaders understand the importance of well designed learning and working environments and can facilitate the development of appropriate diversity student placements and specialist assignments that represent student and classroom support needs accurately. Efficient leaders are committed to the success of all students and collaborate with others to achieve education for all.

In conclusion, in order to advance inclusive education in regular education system they addressed that special bonus for special needs teachers, special incentives for children with special needs, improving school environment, working in attitude change of regular teachers and headmasters, producing skillful professionals, increasing awareness in parental level as well as in the community.

\section{Summary}

Five major themes emerged from the analysis. The themes consisted of issues related to current educational status of students with special needs in terms of knowledge of inclusive education, practices of inclusive education, environmental, and administrative, social and academic challenges, enrolment, retention and 
dropout, roles of school headmasters, districts, zone and region education offices to enhance the effectiveness of inclusive education and efficiency of teachers. The purpose of the interview was to obtain information and their practices from education experts in inclusive education under the above five main headings.

Regarding the knowledge of inclusive education most of the principals, district, zones and region education experts responses for the first question was that they took special needs education as a common course at the higher institution, workshops, seminars, some of them after the assignment of offices and others on the basis of awareness level. When they forwarded their familiarity of inclusive education, since it is in the constitution and on child right, education policy and strategy, and different international and national conventions of human rights. Through assignment of office task leading carefully and understanding policy direction and education systems are basis for familiarity in inclusive education. Further, they addressed that it is current government's agenda.

Concerning the enrollment, retention and dropout of students with special needs, most of the education experts reported that currently the number of children with disabilities and special needs enrollment rates are increasing from time to time. They elaborated about the enrollment progress of the schools positively, parents started to send their children; teachers are started admitting children with disabilities in regular schools. However, a significant number of children who started primary schools are not completing the first cycle because of inadequate treatment, support and unfriendly learning environment of regular classrooms.

Regarding inclusive practices education experts reported that most of the schools are not able to accommodate learners with various diversities. This is because of the prevailing barriers in their education, social, political and economic conditions. The participants reported that school barriers as lack of understanding of the inclusion philosophy by the teachers and others schools communities, poor teaching and learning approaches, inadequate adaptations in public and private buildings to allow easy access and mobility of persons with disabilities, fear of responsibility and stress from added responsibility, lack of early screening, identification and intervention, etc. are some of current challenges. The limitation of professionals who will screen and sort out with their interest of learning is current school's challenge. Therefore, in training professionals a lot of task is remaining for the region.

Most of education experts of the region reported the challenges for the implementation of inclusive education are limited or no material and professionals support in most schools, lack of budget, limited utilization of professionals, identifying and assessment problems of children in different categories, material and moral support limitation for professionals, lack of responsible personnel in all levels, most of inclusive activities run by schools efforts, no budgetary plan to expand inclusive education unless school grant, lack of conducive learning environment still negative attitude of teachers, and community awareness problems are some of the common challenges. All experts believed that it is necessary 
to assign special needs education professional in all level of teaching and learning educational hierarchies.

Most schools are not ready to accommodate diversity of learners. Teachers are not ready in attitude, profession, knowledge and skill. Only limited special needs groups are beneficiaries to some extent like hearing, visual and physical impairments in schools. Almost no provision of the rest groups of diversity learners.

The participants forwarded that inaccessible environment for learners with special needs in infrastructure, resource materials, classrooms and material arrangements are biggest challenges. Most of the learning centers are physically inaccessible because they were not built with ramps to accommodate the physically disabled learners. The sizes of desks and spaces in the classrooms to cater for all learners who use crunches or wheelchairs are some common challenges in the schools. Learners to teacher ratio are not proportional because of large class sizes. Each and every individual needs are not understood very carefully by teachers.

Regarding educational challenges, education experts addressed that there are challenges during including children with disabilities. Teachers are not ready/ committed to support, modify the curriculum based on their interest and ability because teachers are not equipped with skill and knowledge to handle the variety groups. In addition, the resistance of change, office holders' educational experts is one of the challenges for the implementation of the inclusive education. Some districts they don't want to ask trained professionals and even they don't want to send teachers for in-service training of special needs education.

The education experts addressed that the major education burden is lack of knowledge, skill positive attitudes and experiences towards diversity of learners and improper use of professionals. However, at present, the region wanted to revise the teaching and learning process core-education sector from region to district level. Particularly to assign special needs professionals in each level because the structure itself has its own limitation.

\section{Conclusions}

The current study explored the practices, challenges and opportunities of inclusive education implementation in seven regular primary schools of seven districts in Kambata Tembaro zone. The study assessed their practices, challenges and opportunities in the implementation of inclusive education. In addition, it provided information to address qualitative approach with research questions. It produced data that could inform decision makers, principals, districts, zone, and region education experts about current condition of inclusive education.

Concerning the practices of inclusive education, the experts revealed that valuing pupils with special needs in the inclusive classroom no doubt implies adaptation of the standard curriculum. In addition, they addressed that pupils with special needs may require more instruction time or other teaching methods and professional knowledge. In that case, teachers fear the need for more time, more responsibility, materials and knowledge. They reported some problems 
like lack of understanding of the inclusion philosophy by the teachers. The education experts added that poor teaching and learning approaches, inadequate adaptations in public and private buildings allow easy access and mobility of persons with disabilities, fear of responsibility and stress from added responsibility, lack of early screening, and intervention, etc. The findings revealed that there are limitations of professionals' identification, material and resource support and responsibility and encouragement to promote inclusive education.

Education experts stated that most schools' availability and accessibility of the physical facilities including drinking water, electricity, toilets, furniture, playgrounds, libraries, laboratories, resource rooms are not fulfilled, which have a significant impact in academic and vocational achievement of diverse learners. They elaborated practices of schools that children with disabilities and special needs come to schools with diversified needs and interests of learning. This diversified interest of learning requires knowledge, attitude and skill of teaching and treatment. These children with lack of skilled and experienced teachers' treatment in regular classrooms drop out of schools and some again repeat in classrooms. This indicates that lack of knowledge; attitude and skill of teaching and treatment in the schools are the challenges in school performances and implementation of inclusive education.

As experts report most of the teachers are fear of responsibility and stress from added responsibility. They are not free from traditional approaches, practicality, student centered and individualized educational supports are not exercised. Teaching and learning takes place in a haphazard manner, teaching methods are traditional (chalk and talk), teachers are not equipped to match the learners with their diversity needs, and learners suffer with problems of inadequate support. The accommodation of diversity of learners most schools are not ready to accommodate diversity of learners because of negative attitudes of teachers and school communities, teachers are not ready in attitude, profession, knowledge and skill. Only limited special needs groups are beneficiaries to some extent like hearing, visual and physical impairments in schools. Almost no provision for the rest groups of learners.

Regarding curriculum modification both of the region education experts stated that curriculum modifications are not diversity based, most of the learners with special needs are not beneficiaries in regular education system because of no trend of curriculum modification. There is no educational fairness for children with disabilities. This is attributed to the present primary curriculum that doesn't serve the needs of children with disabilities. In this case, many of the children with disabilities learn the curriculum which does not belong to them. Teachers are not supporting these children throughout teaching and learning process by ownership. They are not in liable condition. This finding revealed that there are gaps in education of children with special needs and disabilities and quality of education by itself in inclusive settings.

Most of the education experts reported some environmental challenges for the implementation of inclusive education that schools lack proper and adequate fa- 
cilities and infrastructure such as sanitation facilities, many schools are without ramps, dirty and dusty classrooms and no acoustically treated classrooms. Furthermore, material and professional limitation in schools, lack of budget, still negative attitude of teachers, limited utilization of professionals, identifying and assessment problems of children in different categories, material and moral support limitation for professionals, lack of responsible personnel in districts, schools support limitation in districts, most of inclusive activities run by schools by their own, no budgetary plan to expand inclusive education except common school grant, lack of conducive learning environment and lack of community awareness problem are some of the common challenges.

Concerning education and administrative challenges, their attitudes and actions were a decisive factor for the successful inclusion of children of varied ages and disabilities. The school principals viewed it as their role to create an inclusive atmosphere in their school detrimental. However, society's prejudices, discrimination and negative attitudes are factors that contribute not to play their role in inclusion.

Furthermore, the education experts reported that identifying, screening, documentation of children with disabilities and special needs are big challenge in the schools. Children with disabilities and special needs started to come to school but lack of skilled professionals who will screen and sort with their interest is the current schooling challenges. In all zone districts there is no modern documentation and screening of children with special needs and disabilities. This is home task for the education sectors training skilled professionals and developing screening instruments.

Concerning enrollment, retention and drop out of students with special needs in the zone, all of the participant education experts reported that the current enrollment status of children with disabilities and special needs is encouraging. Majority of the population started to understand inclusive education, parents started to send their children, and teachers started admitting children with disabilities in regular schools. In this regard, enrollment of children with disabilities and special needs improving from previous times.

Education experts have a great role in the implementation of inclusive education changing attitudes of school community as well as society at large exercising the power at the district to region level. Schools with strong administrative support and commitment were able to effectively serve more students with exceptional needs in general education. The school principals are in a better position to identify needs for improvement because of greater contact with students and staffs as well as outside agencies at the same time. They are expected to be the managers of improvement, creating in their schools the right atmosphere for inclusion. Therefore, they have a clear sense of direction for their schools and, in collaboration with their staff, discuss and draw up plans of how to get there. This study displayed that leadership and professional skills are requisite factors in the development of school capacity, and the role of the principals is seen as critical to the delivery of an inclusive educational program. Efficient leaders are com- 
mitted to the success of all students and collaborate with others to achieve education for all. The finding revealed that education experts beginning from school principals to regional levels have a key responsibility in implementation of inclusive education.

Pertaining opportunities to implement inclusive education, most educational experts forwarded that there are fertile international and national conventions, constitutional, education and training policy background for the implementation of inclusive education. Societal, community, and parental attitudes are changing towards person with disabilities from time to time. Regular schools started to admit CWDs and parents started to send their children to regular schools. In different places students with special needs began to learn in special classes/units and in inclusive settings. Special needs professionals are training in different universities and colleges. The regional government started to give due attention for the implementation of inclusive education. Building resource rooms are started in different places of the region. This shows that there is optimistic environment for the implementation of inclusive education.

From this study it is clear that teachers feel that achieving this complex task requires inclusive thinking and action at all levels; adequate and planned funding; proactive leadership within schools; responsive support infrastructure; ongoing professional development and time for joint planning; developing collaborative relationships between schools, parents and support from district, zone and region and other agencies; and effective interventions by support agencies. Societal responses to diversity need to be multifaceted and schools and teachers can play a critical role in enabling children and young people with disabilities to become meaningful participants within society.

\section{Conflicts of Interest}

The author declares no conflicts of interest regarding the publication of this paper.

\section{References}

[1] UNESCO (2005) Guide Lines for Inclusion: Ensuring Access to Education for All. UNESCO, Paris.

[2] UNESCO (2004) The Right to Education for Persons with Disabilities: Towards Inclusion. UNESCO, Paris.

[3] UNESCO (2009) National Report on the Provision of Inclusive Quality Primary and Secondary Education. Inclusive Education Reports Jakarta, Indonesia.

[4] Vincent, C. and Warren, S. (1997) A 'Different Kind' of Professional? Case Studies of the Work of Parent-Centered Organizations. International Journal of Inclusive Education, 1, 143-161. https://doi.org/10.1080/1360311970010202

[5] Ainscow, M., Howes, A., Farrell, P. and Frankham, J. (2003) Making Sense of the Development of Inclusive Practices. European Journal of Special Educational Needs, 18, 22. https://doi.org/10.1080/0885625032000079005

[6] De Boer, A., Pijl, S.J. and Minnaert, A. (2011) Regular Primary School Teachers' Attitudes towards Inclusive Education. International Journal of Inclusive Education, 
15, 331-353. https://doi.org/10.1080/13603110903030089

[7] Ministry of Education (2012) The Second New Special Needs Education Strategy. MOE, Addis Ababa.

[8] SNNPR Education Bureau (2016) House to House Assessment of Children with Disabilities. Hawassa, Unpublished.

[9] Teferra, T. (2005) Disability in Ethiopia: Issues, Insights, and Implications. Addis Ababa University, Addis Ababa. https://doi.org/10.12980/jclm.5.2017j7-151

[10] Lincoln, Y.S. and Guba, E.G. (1985) Naturalistic Inquiry. Sage, Beverly Hills, CA.

[11] Creswell, J. (2007) Qualitative Inquiry and Research Design: Choosing among Five Traditions. Sage, Thousand Oaks, CA. https://doi.org/10.1086/317417 